\title{
LAPISAN BUDAYA KERIS TAMING SARI \\ DALAM HIKAYAT HANG TUAH: \\ PENDEKATAN BUDAYA DAN SEMIOTIK
}

\section{(The Cultural Layers of the Keris Taming Sari in Hikayat Hang Tuah: A Cultural and Semiotics Approach)}

\author{
Sohaimi Abdul Aziz \\ soaazz@usm.my \\ Pusat Pengajian Ilmu Kemanusiaan, \\ Universiti Sains Malaysia.
}

Terbit dalam talian (published online): 8 Julai 2020

Sila rujuk: Sohaimi Abdul Aziz. (2020). Lapisan Budaya Keris Taming Sari dalam Hikayat Hang Tuah: Pendekaan Budaya dan Semiotik. Melayu: Jurnal Antarabangsa Dunia Melayu, 13(2), 319-338.

\begin{abstract}
Abstrak
Keris dianggap sebagai senjata pendek tradisional Melayu. Keris Taming Sari merupakan alat senjata yang istimewa kepada Hang Tuah dalam Hikayat Hang Tuah. Keris ini bukan sahaja senjata orang Melayu tradisional tetapi juga lambang budaya masyarakat Melayu. Namun begitu, belum ada lagi kajian secara sistematik dilakukan terhadap keris Taming Sari. Berdasarkan kajian budaya oleh Edgar H. Schein, keris Taming Sari ialah satu organisasi budaya yang mempunyai struktur yang berlapis-lapis. Setiap lapisan budaya pada keris Taming Sari mempunyai makna yang tertentu. Lapisan pertama ialah lapisan artifak dan lapisan kedua ialah lapisan nilai dan kedua-duanya boleh dilihat atau nyata tetapi pada lapisan ketiga maknanya terselindung atau tidak nampak. Maka pendekatan semiotik daripada Roland Barthes diperlukan. Dua kod tanda telah dipilih, iaitu kod simbol dan kod budaya untuk mentafsirkan makna yang ada pada lapisan ketiga itu. Kajian ini mendapati bahawa dalam lapisan pertama, keris Taming Sari mempunyai bentuk yang terdiri daripada tiga bahagian, iaitu hulu, sarung dan mata. Pada lapisan kedua, nilai kepenggunaan nyata, iaitu sebagai keris Taming Sari senjata dan anugerah. Dengan menggunakan kod simbol, lapisan ketiga keris Taming Sari menunjukkan adanya nilai magis dan daulat, manakala melalui kod budaya, lapisan ketiga keris memancarkan dua andaian yang mendasar, iaitu animisme dan feudalisme. Ketiga-
\end{abstract}

(C) Dewan Bahasa dan Pustaka. 2020. This work is licensed under the term of the Creative Commons Attribution (CC BY) (http://creative commons.org/licenses/by/4.0/)

ISSN 1675-6460 e-ISSN 2682-8049 
tiga lapisan budaya ini telah memberikan satu identiti tersendiri kepada keris Taming Sari sebagai artifak budaya dalam masyarakat Melayu.

Kata kunci: Hikayat Hang Tuah, keris Taming Sari, lapisan budaya, kod tanda

\begin{abstract}
The Keris is a short-bladed dagger considered to be the traditional weapon of the Malays. The dagger known as "keris Taming Sari" is the weapon of Hang Tuah in Hikayat Hang Tuah. This keris is not only a traditional Malay weapon but also a symbol of Malay culture. However, there have not been any systematic studies about the keris Taming Sari. Based on the cultural studies of Edgar H. Schein, Taming Sari can be seen as a cultural organization with a layered structure. Each cultural layer has a specific meaning. The first layer is the artifact layer and the second layer is the value layer; both of these are obvious or explicit. However, the third layer is hidden or unseen. For this, it is necessary to use Roland Barthes's semiotics approach. Two codes have been selected, namely the symbolic code and the cultural code, to interpret the meanings within this third layer. This study finds that in the first layer, keris Taming Sari has a form that consists of the hilt, sheath and blade. In the second layer, the usage value is evident, as keris Taming Sari is a weapon and a gift. By using the symbolic code, this third layer of Taming Sari reveals magical and miraculous values, while the cultural code reveals that the third layer indicates two underlying beliefs: animism and feudalism. The three cultural layers together give keris Taming Sari its own identity as a cultural artifact in Malay culture
\end{abstract}

Keywords: Hikayat Hang Tuah, keris Taming Sari, cultural layers, codes

\title{
PENDAHULUAN
}

Salah satu senjata pendek Melayu tradisional yang terkenal dari dahulu hingga sekarang ialah keris. Keris telah dikenali ramai sebagai sejenis senjata tradisional dari seluruh pelosok Asia Tenggara khususnya di Malaysia, Indonesia, Singapura dan Brunei dari kelompok senjata tikam yang lain seperti belati, kerambit dan badik. Walau bagaimanapun belum ada ketetapan yang dipersetujui ramai tentang tarikh sebenar kemunculan keris. Perkataan keris berasal daripada perkataan Jawa "iris" yang bermaksud "memotong" (Mohamad Nazri, 2000). Namun begitu, keris bukan sahaja boleh memotong tapi menikam dan fungsi menikam inilah yang meletakkan keris sebagai senjata bagi mempertahankan diri atau menyerang orang lain. Selain sebagai senjata pendek, keris juga digunakan dalam majlis rasmi seperti 
persandingan, upacara rasmi di istana seperti pertabalan raja atau sultan dan dalam perubatan tradisional. Keris menjadi sebahagian gaya hidup masyarakat Melayu tradisional. Keris dianggap sebagai pelengkap berpakaian pada zaman dahulu dan pada zaman ini konsep yang sama masih wujud khusus apabila berpakaian tradisional seperti baju Melayu. Pada hari ini kebanyakan keris dijadikan koleksi atau perhiasan kerana nilai sejarah dan warisannya. Keris terdapat dalam pelbagai bentuk dan nama. Woolley (1938) telah membahagikan keris kepada tujuh jenis terbesar, iaitu; keris jenis Semenanjung atau jenis Utara, keris jenis Pekakak, keris jenis Jawa, keris jenis Sumatera, keris jenis Bali dan Madura, keris jenis Bugis dan keris jenis Sundang atau jenis Sulak. Nama-nama jenis keris pula berkait dengan bentuk mata, hulu dan sarung keris. Keris bukan sahaja sejenis senjata pendek tetapi juga satu seni yang penting dari segi bentuk dan ukiran yang terdapat pada mata, hulu dan sarungnya. Sebagai satu bentuk seni daripada masyarakat Nusantara, keris mempunyai sejarah sosiobudaya yang panjang dan penting khususnya di alam Melayu ini.

Salah satu keris yang terkenal dari dahulu hingga sekarang ialah keris Taming Sari yang dikatakan berasal dari Pulau Jawa seperti yang diceritakan dalam Hikayat Hang Tuah, iaitu sebuah epik Melayu yang terkenal. Sebelum ini, banyak perbincangan bertumpu pada bentuk dan sejarah keris serta fungsinya keris seperti keris Taming Sari. Walau bagaimanapun belum ada lagi kajian budaya terhadap keris Taming Sari dengan meneliti lapisan budaya seperti yang dikemukakan oleh Edgar Schein (1984) yang ada pada keris tersebut. Daripada lapisan tersebut akan ditemukan makna. Mencari makna pada lapisan ketiga tidak mudah kerana makna itu terselindung berbanding di lapisan pertama dan kedua. Sehubungan itu, pentafsiran yang dibuat perlu dibantu dan bantuan itu diperoleh daripada pendekatan semiotik yang dikemukakan oleh Barthes yang mengemukakan tanda mempunyai kod tertentu. Dengan merungkaikan kod-kod itu maka makna akan tersingkap.

\section{BUDAYA DAN LAPISAN-LAPISANNYA}

Keris Taming Sari merupakan satu organisasi ang mempunyai lapisan budaya. Sebagai organisasi yang mempunyai lapisan budaya, keris membawa dimensi yang luas merentasi ruang dan waktu. Apakah yang dimaksudkan dengan budaya? Dalam konteks antropologi, budaya membawa beberapa pengertian. Edward Barnett Tylor (1832-1917) dalam buku terkenalnya yang bertajuk Primitive Culture (1871) ada membincangkan tentang budaya. Satu petikan yang sangat terkenal dari beliau tentang budaya ialah: 
Culture or civilization, taken in its wide ethnographic sense, is the complex whole which includes knowledge, belief, arts, morals, law, and other capabilities and habits acquired by man as member of society.

(Tylor, 1874, p. 1)

Tylor memberikan definisi budaya dari konteks etnografi, iaitu sains tentang manusia dan budaya. Budaya wujud melalui proses evolusi, iaitu budaya berkembang daripada satu tahap kepada satu tahap seperti daripada tahap primitif kepada tahap moden. Tylor berpendapat bahawa budaya yang meliputi pelbagai aspek seperti pengetahuan, kepercayaan, seni, moral, undang-undang, kelaziman dan pelbagai keupayaan diperoleh oleh manusia daripada masyarakatnya dan hal ini berlaku secara evolusi sosial.

Bagi Tylor, perkembangan budaya berlaku daripada satu generasi kepada satu generasi atau dari satu zaman ke satu zaman yang lain secara evolusi dan hal ini merupakan satu proses yang universal, yakni berlaku dalam mana-mana budaya. Tylor menegaskan lagi, proses pembentukan budaya secara evolusi (cultural evolution) sama dengan pembentukan tamadun. Pengertian proses pembentukan budaya sebagai satu proses evolusi dan universal ini telah dikritik, dan antara kritikan itu adalah daripada Boas (1852-1942). Boas menolak pandangan Tylor atau golongan evolusionis, dengan pandangan bahawa sesuatu persekitaran tempatan mempengaruhi pembentukan budaya. Masa dan ruang yang berbeza membentuk budaya yang berbeza sehingga melahirkan satu keunikan budaya. Pembentukan budaya baharu dipengaruhi oleh satu keadaan yang baharu. Bagi Boas:

We rather see that each cultural group has its own unique history, dependent partly upon the peculiar inner development of the social group, and partly upon foreign influences to which it has been subjected. There have been processes of gradual differentiation as well as processes of leveling down differences between neighboring cultural centers, but it would be quite impossible to understand, on the basis of a single evolutionary scheme, what happened to any particular people.

(dipetik oleh McGee \& Warms 2008, p. 125)

Boaz mengetengahkan konsep budaya yang memberikan perhatian kepada keunikan. Setiap budaya itu unik kerana perkembangannya dipengaruhi oleh faktor dalaman (tempatan) dan faktor luaran seperti pengaruh asing yang datang daripada 


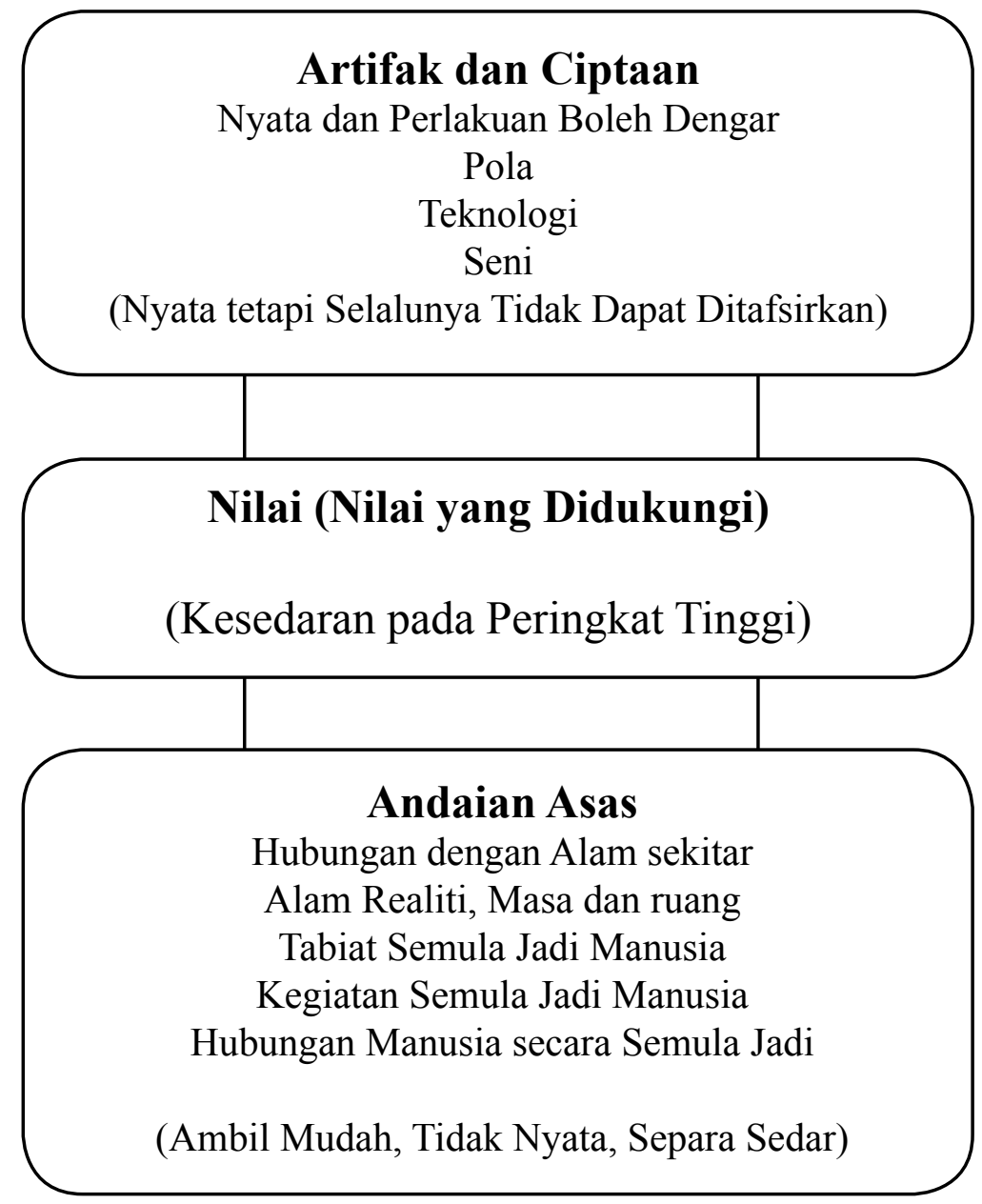

Rajah 1 Lapisan budaya daripada Edger H. Schein (1984, p. 4) yang diubah suai.

pelbagai arah dan bentuk seperti perdagangan, komunikasi dan sebagainya. Keris sebagai satu objek budaya juga tidak terlepas daripada perkembangan budaya yang dimaksudkan oleh Boaz. Keris berkembang seperti yang dinyatakan olen Boaz kerana setiap ruang dan masa yang berbeza membentuk keris yang berbeza bentuknya dan keadaan ini menimbulkan keunikan sesuatu keris itu atau memperlihatkan identiti keris berkenaan. Oleh itu, bertepatan dengan dengan pendapat Woodly bahawa keris boleh dikelompokkan kepada tujuh kelompok besar berdasarkan tempat asalnya.

Selain unsur-unsur pembentukan budaya, satu lagi aspek penting untuk memahami budaya ialah lapisan budaya. Menurut Schein (1984) budaya sebagai 
satu organisasi dapat dianalisis dengan memerhatikan lapisannya. Terdapat tiga lapisan penting dalam memahami dan menganalisis budaya. Lapisan pertama ialah lapisan artifak yang boleh diperhatikan (observable artifacts); lapisan kedua ialah lapisan nilai yang dipersetujui oleh ramai orang. Lapisan ketiga dikenali sebagai lapisan andaian asas yang mendasar (basic underlying assumptions) dan lapisan tidak kelihatan dan sering tidak dipedulikan. Setiap lapisan itu berhubungan. Yang berikut diperlihatkan lapisan budaya dan interaksinya seperti yang dinyatakan oleh Schein (1984, p. 4):

Lapisan budaya yang berbeza-beza tingkat pembentukan maknanya menimbulkan sedikit masalah dan hal ini dapat diatasi dengan menggunakan semiotik sebagai satu pendekatan untuk membuat tafsiran, khususnya pada peringkat lapisan ketiga yang kabur atau tidak kelihatan berbanding dengan lapisan pertama dan kedua.

\section{SEMIOTIK DAN KOD TANDA}

Tanda menjadi satu aspek penting dalam semiotik, iaitu makna dapat dicipta dan dikomunikasikan. Semua tanda bergantung pada sistem tanda tersebut. Dalam kajian semiotik, semua bentuk komunikasi ialah tanda seperti bahasa, imejan, objek, termasuklah keris. Masalahnya, bagaimana untuk melancarkan pentafsiran itu terhadap tanda-tanda yang ada? Kajian semiotik memberikan satu pendekatan yang boleh digunakan untuk mengatasi permasalahan pentafsiran ini. Artikel ini akan menggunakan kajian semiotik yang digunakan oleh Barthes dalam bukunya yang bertajuk $S / Z$ (1974). Dalam buku ini, Barthes telah mengemukakan lima buah kod yang boleh digunakan sebagai cara membuat interpretasi terdapat apa-apa jua bentuk tanda termasuklah keris. Antara kodnya termasuklah kod simbol dan kod budaya.

Apakah yang dimaksudkan dengan kod simbol? Mengikut Barthes, kod simbol membenarkan sesuatu tanda itu ditafsirkan dengan beberapa pentafsiran:

... this is the place for multivalence and for reversibility; the main task is always to demonstrate that this field can be entered from any number of points, thereby making depth and secrecy problematic.

(Barthes, 1974, p. 19)

Tanda merupakan sesuatu yang mempunyai makna dan melalui pentafsiran, tanda menyampaikan makna. Keris yang dianggap sebagai tanda boleh dikaji dengan 
beberapa tafsiran seperti keris bukan sahaja sebagai senjata tetapi juga sebagai representasi budaya. Berdasarkan pandangan Barthes, dalam konteks semiotik, keris diterima sebagai tanda dan untuk menemukan makna tanda itu, kod simbol digunakan. Selain kod simbol, satu lagi kod yang sesuai dan berkaitan ialah kod budaya. Sesuai dengan keris sebagai tanda, kod budaya sangat diperlukan untuk pentafsiran makna dengan lebih mendalam. Di sini peranan pembaca atau pentafsir diberikan perhatian berbanding dengan pencipta artifak tersebut. Mengikut Barthes, kod budaya ialah:

... the cultural codes are references to science or a body of knowledge; in drawing attention to them, we merely indicate of knowledge (physical, physiological, medical, psychological, literary, historical, etc.) referred to, without going so far as to construct (or reconstruct) the culture they express.

(Barthes, 1994, p. 20)

Kod budaya merujuk kelompok pengetahuan tentang apa-apa sahaja yang dapat diperoleh daripada budaya tersebut. Di sini, peranan pembaca sangat penting dalam membuat tafsiran. Pengalaman dan pengetahuan pembaca mempengaruhi penggunaan kod budaya ini. Pengetahuan itu mungkin berkaitan dengan psikologi, perubatan dan sebagainya. Dalam konteks kajian ini, kod budaya yang akan digunakan untuk mentafsirkan keris juga merujuk beberapa pengetahuan seperti kepercayaan, sistem masyarakat, nilai, adat istiadat dan sebagainya yang merupakan lapisan andaian yang dasar.

\section{KERIS TAMING SARI}

Keris Taming Sari merupakan sebilah keris yang mempunyai banyak cerita tentangnya. Salah satu cerita yang masyhur tentang keris Taming Sari terdapat dalam Hikayat Hang Tuah. Mengikut Kassim Ahmad (1997), Hikayat Hang Tuah merupakan epik Melayu atau karya klasik Melayu yang agung yang memancarkan kebesaran bangsa Melayu dari mula hinggalah ke zaman penjajahan Portugis. Epik ini ditulis pada tahun 1641 (berdasarkan unsur sejarah yang terdapat pada hujung hikayat ini), khususnya selepas kejatuhan kota Melaka kepada Portugis atau Feringgi. Hang Tuah sebagai tokoh utamanya hampir mewakili sudut pandang alam bangsa Melayu seperti yang dapat ditafsirkan melalui keris Taming Sarinya. 
Mengikut Hikayat Hang Tuah, keris Taming Sari ialah keris milik seorang pendekar Jawa bernama Taming Sari. Hang Tuah memiliki keris ini daripada Taming Sari dengan muslihat dalam satu pertarungan sengit antara kedua-duanya di Istana Paduka Seri Betara Majapahit ketika mengiringi rombongan Raja Melaka untuk melangsungkan perkahwinan dengan Raden Galuh Emas Ayu Puteri Majapahit. Apabila rombongan diraja Melaka tiba di istana Seri Betara Majapahit, muncul seorang pendekar Jawa yang bernama Taming Sari dan memohon izin daripada Rajanya untuk menentang pahlawan daripada Melaka. Setelah diperkenan oleh Sultan Melaka, tampillah Hang Tuah ke gelanggang untuk bertarung melawan Taming Sari. Setelah Hang Tuah berjaya membunuh Taming Sari, sebagai balasannya Seri Betara Majapahit menganugerahkan keris itu kepada Hang Tuah dan memberi gelaran Laksamana. Sultan Melaka yang sangat sukacita turut memberi restu dan menganugerahi sandang persalinan selengkapnya. Dengan kata lain, keris Taming Sari yang dibincangkan dalam artikel ini ialah keris yang terdapat dalam cerita teks Hikayat Hang Tuah. Sehingga hari ini, belum terdapat bukti sejarah wujudnya keris Taming Sari sungguhpun terdapat pandangan bahawa keris Taming Sari ada dalam simpanan Sultan Perak.

Keris Taming Sari bukan sahaja sebagai alat senjata tetapi lebih daripada itu. Keris Taming Sari mempunyai cerita roman dan pengembaraan, kebangsawanan, tradisi dan kepahlawanan. Menurut Sulastrin Sutrisno (yang ambil daripada Noriah Mohamed, 1977, p. xxxviii), Hikayat Hang Tuah merupakan sebuah karya yang memberikan gambaran yang jelas tentang sistem nilai atau sistem budaya masyarakat Melayu pada suatu tempat dan masa. Pendek kata, keris Taming Sari mempunyai kedudukan yang penting dalam masyarakat Melayu. Artikel ini akan membincangkan keris Taming Sari sebagai satu organisasi budaya yang mempunyai lapisan-lapisannya.

\section{Lapisan Pertama: Keris Mempunyai Bentuk}

Pada lapisan pertama, keris Taming Sari ialah lapisan artifak dan sebagai artifak, makna kepada lapisan pertama adalah jelas dan boleh diperhatikan. Pada lapisan pertama ini, keris Taming Sari diterima sebagai peralatan buatan manusia peninggalan zaman dahulu yang mempunyai bentuk tertentu dan mudah dilihat. Dari sudut sejarah, keris berasal dari alam Melayu yang berusia ratusan tahun dan ada yang percaya sudah berusia ribuan tahun. Maka keris dianggap sebagai pusaka Melayu dan mendapat tempat kedudukan yang istimewa dalam masyarakat Melayu dahulu hingga sekarang. Pada peringkat lapisan pertama ini, keris, seperti Taming Sari, ialah objek yang 
boleh diperhatikan secara fizikal. Bentuknya terbahagi kepada beberapa bahagian, iaitu hulu, sarung dan mata. Bentuknya yang kuno (keris buda atau sombro), senjata ini tidak bercorak kerana tidak ada pamor (campuran beberapa logam), lurus (tidak berluk) dan pendek. Kemudian pembentukan pamor menjadi salah satu aspek penting dalam pembuatan keris yang bermutu kerana pamor mempamerkan motif-motif tertentu. Terdapat juga motif-motif tersebut ditempelkan kepada keris tanpa proses pamor.

Berdasarkan kajian ikonografi bangunan dan gaya ukiran di beberapa candi seperti di Sumatera Utara dan Pulau Jawa, keris moden mengikut pengertian kontemporari berasal dari kerajaan Srivijaya (abad ke-11) di Sumatera dan ada yang mengatakan bermula pada zaman Majapahit (abad ke-13 hingga ke-15). Dari sudut bentuknya, keris merupakan senjata tajam yang berfungsi untuk menikam mangsanya. Bentuk keris itu meruncing ke hujungnya dan bermata dua serta tajam pada kedua-dua sisinya. Oleh sebab bentuk tajam dan meruncing maka keris mempunyai hulu dan sarung. Pada dasarnya, bentuk keris terbahagi kepada tiga komponen, iaitu mata keris, hulu keris dan sarung keris. Setiap komponen itu mempunyai bahagian-bahagian tertentu seperti pada bahagian keris terdapat hujung keris, pamur, tulang keris dan mata keris. Di hulu keris pula terdapat hulu dan pendongkon, manakala sarung keris pula mengandungi sampir, batang dan buntut keris (Mas Djomul, 1985). Dalam konteks keris Taming Sari, bentuknya jelas, iaitu mempunyai hulu, sarung dan mata. Namun bahagian-bahagian daripada bentuk tersebut tidak dirincikan dalam Hikayat Hang Tuah.

\section{Lapisan Kedua: Keris sebagai Senjata dan Anugerah}

Pada lapisan kedua, keris Taming Sari mempunyai nilai, dan nilai tersebut bersifat pada permukaan dan dipersetujui ramai. Nilai keris pada lapisan kedua ini merujuk nilai kepenggunaannya. Keris Taming Sari digunakan sebagai senjata yang boleh membunuh atau mempertahankan diri. Umumnya, masyarakat Melayu menerima keris sebagai senjata pendek yang wujud semenjak dahulu lagi. Keris sebagai senjata ada dijelaskan oleh Shahrum Yub dalam petikan berikut:

Keris ialah sejenis senjata pendek kebangsaan Melayu turun-temurun yang telah digunakan oleh orang-orang Melayu sejak lebih daripada 600 tahun yang lalu dan dari beberapa banyak senjata-senjata Melayu telah mendapat tempat yang istimewa kerana dijadikan sebagai lambang kemegahan bangsa dan negara. Keris bukan 
sahaja digunakan sebagai senjata untuk mempertahankan diri, tetapi juga sebagai alat kebangsaan Diraja.

(Shahrum, 1967, p. 1)

Keris Taming Sari juga diterima sebagai senjata yang cukup istimewa kepada pemiliknya. Dalam Hikayat Hang Tuah, keris Taming Sari telah digunakan sebagai senjata oleh dua pendekar di Melaka, iaitu Hang Tuah dan Hang Jebat. Keris Taming Sari dikatakan berasal daripada seorang pendekar dari Jawa yang bernama Taming Sari. Daripada nama pendekar ini, keris tersebut mendapat namanya. Hang Tuah telah dianugerahkan keris tersebut oleh Raja Majapahit kerana berjaya menumpaskan Taming Sari dalam satu pertarungan yang sengit. Pertarungan klasik dalam Hikayat Hang Tuah ini, Hang Jebat yang dikatakan telah menderhaka kepada Sultan Melaka telah dibunuh oleh Hang Tuah dengan menggunakan keris Taming Sari. Yang berikut diperlihatkan pertarungan tersebut:

Maka kata Hang Jebat, "Hai laksamana, baik-baiklah engkau menantikan tikam Si Jebat derhaka ini," seraya diusirnya akan laksamana lalu ditikamnya di dada laksamana. Maka laksamana pun tiada sempat menghunus kerisnya. Maka oleh Jebat dipertubi-tubinya tikam akan laksamana. Maka laksamana pun segera menghunus kerisnya serta berguling di atas talam itu. Maka oleh Hang Jebat maka dipertubitubinya tikam, kerana pada tubuh laksamana, kena talam itu terus tiada bertahan. Maka Hang Jebat pun lelah, tetapi sungguhpun laksamana berguling mata kerisnya ke atas juga. Syahadan keris Hang Jebat pun sebagai lekat pada talam itu. Arkian maka laksamana pun segera berbangkit berdiri, serta katanya, "Cih, mati engkau olehku!" Maka laksamana pun melompat serta ditikamnya dada Hang Jebat, kena dadanya terus bayang-bayang ke belakangnya.

(Hikayat Hang Tuah, 1997, p. 391)

Sebelum itu, berlaku pertarungan antara Hang Tuah dengan Taming Sari.

Maka Tun Tuah pun melompat ke kanan dan ke kiri menyalak tikam Taming Sari itu, seperti tiada berjejak di bumi lakunya. Maka Taming Sari pun lelah ternganganganga seperti anjing lelah. Maka Tun Tuah pun Melompat serta ditikamnya dada Taming Sari, serta katanya, "Cih, mati penjurit Taming Sari olehku!" Maka ditikamnya, kena dadanya terus berbayang-bayang ke belakangnya. Maka Taming Sari pun rebah tersungkur, lalu mati.

(Hikayat Hang Tuah, 1997, p. 167) 
Selain nilai keselamatan yang ada pada keris Taming Sari apabila digunakan sebagai senjata, keris Taming Sari juga diterima sebagai anugerah oleh Seri Betara Majapahit. Keris Taming Sari dianugerahkan kepada Hang Tuah sebagai penghormatan kepadanya setelah dapat mengalahkan dan membunuh Taming Sari yang mengamuk di peseban istana Majapahit. Petikan berikut merakamkan upacara penganugerahan tersebut:

Maka keris Taming Sari itu dipersembahkannya oleh Tun Tuah pada Seri Betara. Maka dilihat oleh Seri Betara keris itu; maka titah Seri Betara, "Adapun keris ini anugerah kitalah pada Kiai Tuah itu....

(Hikayat Hang Tuah, 1997, p.167)

Pada lapisan kedua ini, cukup jelas nilai budaya pada keris Taming Sari. Keris ini mempunyai nilai kepenggunaan atau lebih tepat lagi nilai keselamatan, iaitu menjadi senjata menyerang dan membunuh musuh serta mempertahankan diri. Adegan pertaruhan antara Hang Tuah dengan Taming Sari dan Hang Jebat membuktikan nilai ini. Keris Taming Sari juga mempunyai nilai anugerah atau hadiah yang tinggi nilainya apabila keris ini dianugerahkan oleh Seri Betara Majapahit kepada Hang Tuah.

\section{Lapisan Ketiga: Keris Sebagai Cerminan Pemikiran}

Lapisan ketiga budaya merupakan lapisan yang tidak boleh dilihat tetapi sarat dengan makna yang perlu ditafsirkan. Makna-makna ini pula berkaitan dengan dasar, dan dasar yang dimaksudkan ialah pemikiran. Bagi tujuan pentafsiran, pendekatan semiotik digunakan dan semiotik yang dikemukakan oleh Barthes didapati sesuai. Barthes telah mengemukakan beberapa kod yang dapat memudahkan pentafsiran. Bagi Barthes, apa-apa sahaja boleh dianggap sebagai tanda termasuklah budaya dan keris Taming Sari tidak terkecuali. Dalam pendekatan semiotik, seperti yang telah dijelaskan bahawa keris Taming Sari bukanlah hanya sebagai senjata tetapi sebagai tanda yang mempunyai makna yang tersirat. Dalam konteks antropologi, golongan ahli antropologi simbolik (simbolic anthropologists) telah memberikan perhatian kepada budaya sebagai salah satu simbol. Bagi memahami budaya sebagai satu simbol maka aspek interpretasi sangat penting diberikan penekanan untuk mendapatkan maknanya: 
Symbolic anthropologists argue that, like language, symbols are shared system of meaning that can be understood within a particular historical and social context. Culture, they believe, lies in people's interpretations of the events and things around them. In other words, symbolic anthropologists believe we construct our cultural reality. Consequently, they take a thematic approach, focusing on the analysis of meaning.

(McGee and Warms, 2008, pp. 482-483)

\section{(1) Magis dan Animisme}

Sesiapa yang memiliki keris Taming Sari mempunyai kuasa yang luar biasa seperti tidak lut ditikam dengan apa-apa jua senjata. Mengapakah keris Taming Sari begitu berkuasa sehingga pemiliknya menjadi kebal? Dalam satu peristiwa ketika Hang Tuah telah dihukum bunuh oleh Raja Melaka kerana termakan fitnah oleh Patih Kerma Wijaya. Hang Jebat yang menyedari tindakan Raja tanpa usul periksa itu telah membela nasib sahabatnya itu yang telah teraniaya dengan menduduki Istana Melaka. Amukan Hang Jebat telah menyebabkan Raja berasa kesal dengan tindakan baginda itu dan mengarahkan Hang Jebat dibunuh. Hang Jebat telah dilabelkan sebagai penderhaka dan diperlu dihapuskan. Namun begitu, tidak ada seorang pendekar Melaka yang mampu melakukannya. Lalu Hang Tuah yang tidak dibunuh tetapi disembunyikan oleh Bendahara Melaka di dusunnya di hulu Melaka telah diminta kembali. Hang Tuah telah diperintah oleh Raja untuk membunuh Hang Jebat. Namun begitu, Hang Tuah memaklumkan kepada Raja bahawa tidak akan ada sesiapa yang boleh melakukannya kerana keris Taming Sari berada di tangan Hang Jebat:

Maka sembah Laksamana, "Daulat tuanku, patik memohon ampun, patik pohonkan keris pandak patik supaya patik pergi membuangkan Si Jebat derhaka itu." Maka titah raja, "Ayo Laksamana, keris itu sudah kita berikan Si Jebat derhaka itu." Setelah Laksamana mendengar titah raja demikian itu, maka Laksamana pun menampar-menampar pahanya seraya berkata, "Wah, sayangnya keris itu beroleh akan Si Jebat. Siapatah dapat berhadapan dengan dia?"

(Hikayat Hang Tuah, 1997, p. 349)

Keris pandak yang dimaksudkan oleh Hang Tuah ialah keris Taming Sari. Dalam petikan ini menunjukkan bahawa Hang Jebat kebal dengan sebarang senjata selagi 
keris itu bersamanya. Hang Jebat tidak dapat dibunuh atau dihapuskan seperti yang dititahkan oleh Raja jika keris Taming Sari masih di tangan Hang Jebat.

Kesaktian keris Taming Sari ini dapat dilihat semenjak di Pulau Jawa, iaitu tempat asal usulnya. Dalam pergelutan antara Hang Tuah dengan pendekar Taming Sari di peseban istana Majapahit, Hang Tuah menyedari kesaktian keris Taming Sari. Pengguna Taming Sari kebal daripada dilukakan atau ditikam olehnya:

Maka segala orang banyak pun suka melihat Tun Tuah bertikam dengan Taming Sari itu. Maka Tun Tuah pun fikir dalam hatinya, "Apa juga dipakainya maka tiada lut kuparang? Tetapi pada firasatku sebab kerisnya inilah maka ia tiada dapat ditentang lawan dan tiada lu kuparang tubuhnya itu. Jikalau demikian, apa juga kehendaknya? Baiklah kerisnya ini kuperdayakan.”

(Hikayat Hang Tuah, 1997, p. 155)

Kemudian dalam satu peristiwa yang lain, Patih Gajah Mada berusaha mencuri keris Taming Sari kepunyaan Hang Tuah. Bagi menjalankan rancangannya itu, Patih Gajah Mada menjemput Raja Melaka dan Hang Tuah untuk meriwayatkan kisah raja-raja dahulu kala. Semasa Hang Tuah asyik bercerita, pencuri upahan Patih Gajah Mada, Bima Sina Pati telah mencuri keris Taming Sari daripada Hang Tuah. Hang Tuah yang berwaspada dan cerdik itu berjaya juga mendapatkan kembali keris daripada Patih Gajah Mada. Apabila Betara Majapahit mengetahui apa yang berlaku, Patih Gajah Mada dikehendaki mengembalikan keris Taming Sari kepada Hang Tuah. Kemudian Hang Tuah juga mengembalikan keris Patih Gajah Mada. Akhirnya, Patih Gajah Mada mendapat malu. Dalam perbincangannya untuk mencuri keris Taming Sari itu, beliau ada mengatakan tentang keris Taming Sari:

Patik dengar daripada segala perajurit yang tua, jikalau ada keris Taming Sari itu pada Laksamana, bahawa sekali-kali Laksamana tiada mati oleh senjata, kerana kerisnya Taming Sari itu tiada dapat ditentang oleh lawan; kerana sebab itulah tatkala Taming Sari mengamuk itu, maka tiada dapat ditentang oleh lawan.

(Hikayat Hang Tuah, 1997, p.167)

Keris Taming Sari yang luar biasa kuasanya merupakan simbol kepada suatu nilai yang berkaitan dengan kuasa yang menyebabkan pemiliknya menjadi kebal daripada sebarang tusukan senjata tajam seperti lembing atau keris. Kod simbol yang 
digunakan untuk mentafsirkan keris Taming Sari menunjukkan keris ini mempunyai nilai magis, dan nilai magis ini diberitahu sendiri oleh Hang Tuah kepada Raja dan oleh Patih Gajah Mada kepada Seri Betara Majapahit. Nilai magis keris Taming Sari dapat dilihat daripada penyataan Hang Tuah dan Patih Gajah Mada, dan dibuktikan melalui tingkah laku pertarungan antara Hang Tuah dengan Hang Jebat dan Taming Sari. Nilai seperti ini merupakan satu nilai dukungan (espouse) dan nilai ini membawa kepada satu lapisan budaya ketiga yang lebih mendasar atau dasar andaian. Melalui kod simbol, keris Taming Sari boleh diterima sebagai satu simbol, iaitu satu simbol magis. Keris Taming Sari mempunyai kuasa magis yang luar biasa sehingga sesiapa yang menggunakannya akan memiliki kuasa magis itu. Nilai magis yang terdapat pada keris Taming Sari antaranya bertujuan untuk mengangkat kehebatan kepahlawanan Hang Tuah (Kassim Ahmad, 1979, pp. xiv-xv).

Kod simbol ini diperkuat dengan kod budaya untuk memahami keris Taming Sari sebagai satu simbol magis. Tegasnya, melalui kod budaya makna dalam lapisan ketiga ini dapat diketahui dengan lebih mendalam lagi. Melalui kod budaya, nilai magis yang ada pada keris Taming Sari dapat difahami dengan merujuk pemikiran tradisional Melayu yang dikenali sebagai animisme. Dalam masyarakat Melayu tradisional, sebelum munculnya agama, animisme menjadi pegangan dan berasaskan kepada doktrin roh. Dalam bidang antropologi, animisme merupakan suatu kepercayaan masyarakat primitif atau kuno yang yakin bahawa segala sesuatu yang wujud di muka bumi ini mempunyai roh atau semangat. Pegangan primitif ini mengalami penyesuaian dengan keadaan seperti terbentuknya budaya (Tylor, 1974, p. 452). Masyarakat primitif seperti masyarakat Melayu sebelum kedatangan Islam percaya kepada animisme. Tegasnya, pengaruh animisme telah menguasai masyarakat Melayu pada zaman Hang Tuah. Tambahan pula ajaran Islam tidak kelihatan kukuh dalam Hikayat Hang Tuah. Rasionalnya nilai animisme menguasai Hang Tuah dan sangat kukuh. Pengalaman pembaca memahami animisme dapat membantu pembaca menggunakan kod budaya untuk memahami lagi nilai magis ini. Melalui pembacaan terhadap pandangan pembaca dapat memahami lagi mengapa keris Taming Sari memiliki nilai magis. Dengan kata lain, nilai magis pada keris Taming Sari ada kaitannya dengan pengaruh animisme terhadap masyarakat Melayu zaman dahulu yang percaya bahawa keris mempunyai roh.

Nilai magis yang ada pada keris juga dikaitkan dengan pembuatan keris. Selain pembuatnya (empu) itu manusia yang mempunyai keahlian yang luar biasa, empu juga mempunyai ilmu batin yang pancarannya tembus dan masuk ke dalam keris ciptaannya (Mas Ngabehi Wirasoekadga, 1988). Selain faktor empu, keris 
mempunyai nilai magis kerana ada kaitannya dengan bahan dan cara pembuatan keris tersebut. Misalnya, logam yang membuat mata keris, pamor, sarung dan hulunya. Mengikut Ki Hudoyo:

Daya Magik yang menyelimuti bilahan keris, mempunyai misi tersendiri dalam kehidupan pemilik pusaka itu. Daya Magik itu terdapat pada besinya secara alami, daya magik itu dapat berasal dari pamor menurut motifnya, dan daya magik itu bisa juga terdapat pada motip kerisnya atau dapurnya kerisnya, dan terpenting adalah daya magik yang diciptakan oleh empu penciptanya.

(Ki Hudoyo Doyodipuro, Occ, 2000, p. 18)

Dengan kata lain, nilai magis yang datang daripada empu dan pembuatan keris termasuklah keris Taming Sari sebenarnya ada kaitan dengan animisme. Budaya animisme menguasai dunia keris termasuklah keris Taming Sari.

\section{(2) Daulat dan Feudalisme}

Keris Taming Sari berada dalam dua ruang kerajaan, iaitu Kerajaan Melayu Melaka dan Kerajaan Majapahit yang penuh dengan peraturan-peraturan rasmi di dalam istana seperti istiadat mengadap raja, pertabalan raja, menerima rombongan dari luar negara dan sebagainya. Kebangsawanan mewarnai keberadaan keris Taming Sari dan kebangsawanan ini lebih hidup dengan adanya drama pertikaman antara Hang Tuah dengan Hang Jebat dan Hang Tuah dengan Taming Sari di istana raja masing-masing. Kebangsawanan itu ada kaitannya dengan daulat. Kerajaan Melaka dan Majapahit mempunyai kedaulatan yang sering juga digugat. Pertarungan ini telah menyaksikan bagaimana keris Taming Sari memainkan peranan yang penting dalam kedaulatan kedua-dua kerajaan.

Daulat ini merujuk kuasa, iaitu kuasa yang tertinggi terhadap sesuatu. Kerajaan Melayu Melaka berdaulat bermaksud kerajaan itu mempunyai kuasa yang tertinggi atas negeri-negeri yang lain yang dikatakan menjadi negeri-negeri naungannya. Dalam kajian Tengku Intan Marlina dan Salina Ja'afar (2013), keris Taming Sari menjadi alat kebesaran kepada kedua-dua kerajaan dan hal ini diperlihatkan apabila keris Taming Sari dianugerahkan kepada Hang Tuah sebagai suatu penghormatan setelah dapat membunuh Taming Sari yang mengamuk di peseban istana Majapahit dan keris yang sama diberikan kepada Hang Jebat setelah dilantik sebagai Laksamana menggantikan Hang Tuah. Artikel ini pergi lebih jauh daripada 
itu dengan menggunakan kod simbol, iaitu keris Taming Sari melambangkan daulat yang memberi kesan kepada Hang Tuah, kerajaan Melaka dan Majapahit.

Kod simbol juga dapat digunakan untuk menjelaskan lagi nilai daulat. Hal ini jelas pada penghujung cerita apabila Hang Tuah dan Raja menjadi lemah kerana hilangnya keris Taming Sari di dalam sungai. Ketika mengikuti rombongan Raja Melaka ke Singapura, mahkota Raja Melaka telah terjatuh ke dalam sungai. Maka Hang Tuah telah menyelam untuk mendapatkan mahkota tersebut dan berjaya mendapatkannya. Ketika menghampiri perahu Raja, seekor buaya putih telah menyambar keris yang ada di tangan Hang Tuah. Raja telah hilang mahkotanya dan Hang Tuah pula telah kehilangan keris Taming Sarinya. Masing-masing menerima kesan daripada kehilangan tersebut:

Tetapi tubuh baginda selama hilang mahkota itu tiadalah baik, gila-gila dengan sakit kepalanya dan demam. Bermula Laksamana pun demikianlah juga selamanya hilang kerisnya itu, gila-gila dengan sakit kepalanya dan tubuhnya demam. Maka ia pun tahulah akan dirinya.

(Hikayat Hang Tuah, 1997, pp. 479-480)

Terdapat dua simbol di sini, iaitu mahkota Sultan Melaka dan keris Taming Sari. Mahkota Raja Melaka ini dapat diasosiasikan dengan kuasa tertinggi seorang raja iaitu daulat. Keris sering dikaitkan dengan sejenis senjata. Namun begitu, melalui kod simbol, keris Taming Sari yang hilang di sungai ini merupakan juga simbol kuasa tertinggi, iaitu daulat. Kedua-duanya telah hilang di sungai. Kehilangan keduaduanya memberi kesan fizikal yang sama kepada Raja dan Hang Tuah. Kehilangan daulat ini dapat dirasakan kemudian apabila kerajaan Melaka telah diserang oleh kuasa Barat, iaitu Feringgi:

Maka segala rumah dan pagar dan balai dan jambatan orang Melaka itu pun habislah diterbangkan oleh peluru meriam itu. Maka kapal Ferenggi di negeri Manila dan Portugal pun datanglah empat puluh buah membantu temannya.

Maka orang Melaka pun terkejutlah terlalu huru-hara, beribu-ribu yang mati dan luka kena bedil: ada yang kena peluru kena pegawai rumahnya, ada yang kena pagarnya, ada yang kena pegawai jambatan. Dengan demikian orang yang berketi- 
keti banyaknya itu habis lari membawa dirinya ke hulu Melaka, pecah-belah, tiadalah lagi berketahuan perginya.

(Hikayat Hang Tuah ,1997, p. 545)

Serangan Feringgi terhadap kerajaan Melaka diikuti oleh serangan dan penguasaan Wolanda (Belanda). Apabila runtuh Kerajaan Melayu Melaka, dibina pula di negeri Johor. Hang Tuah tidak lagi disebut-sebut di Melaka. Hang Tuah dikatakan tidak mati tetapi dipercayai menghilangkan diri dan berada di hulu Perak.

Kewujudan nilai daulat pada keris Taming Sari ada hubungannya masyarakat di mana Hang Tuah itu hidup. Masyarakat Melayu dalam Hikayat Hang Tuah merupakan masyarakat Melayu yang pengaruh Islamnya belum kukuh. Pola masyarakatnya yang berhierarki, iaitu "Raja dan Hamba." Kerajaan Melaka dan Majapahit memusatkan kuasa mereka kepada raja dan rakyat menjadi hamba. Raja dan keluarganya serta para pembesar dalam hierarki tertinggi dalam masyarakatnya. Golongan Raja berkuasa dan kekuasaannya diterima oleh rakyat disebabkan Raja-Raja ini dipercayai datang dari dunia kayangan, maka mereka mempunyai daulat. Dengan kata lain, daulat yang maksudkan ialah daulat yang ada kaitannya dengan unsur-unsur magis. Rakyat dituntut untuk taat dan setia kepada raja-raja ini. Masyarakat seperti ini kenali sebagai masyarakat feudal.

Perbezaan darjat antara rakyat dan Raja dikonkritkan dengan bentuk keris Taming Sari berbanding dengan beberapa keris Sultan Mansor. Keris Taming Sari tidak dirincikan bentuknya kerana berkemungkinan pengarang Hikayat Hang Tuah tidak mahu menyamakan antara keris Taming Sari dengan keris milik Sultan seperti keris Parung Sari, keris Sempana dan keris Paduka Marhum di Bukit Siguntang yang menjadi milik Sultan Mansor. Misalnya, keris Sempana memiliki mata keris ini yang diperbuat daripada tembaga dan suasa, sarungnya bertatahkan emas yang dipahat, dihias dengan permata merah dan berantai (Hikayat Hang Tuah, p. 376). Sungguhpun dari segi fizikal dua keris ini (keris Taming Sari dan keris Sempana) berbeza, namun dari segi kuasa magisnya, keris Taming Sari lebih berkuasa dan penggunanya akan menjadi lebih perkasa dan handal dalam arena pertarungan seperti pertarungan antara Hang Tuah dengan Hang Jebat.

Keris Taming Sari juga mempunyai nilai daulat dan sesiapa yang memilikinya akan diterima sebagai orang yang berkuasa dan patut digeruni. Daulat di sini ada kaitannya dengan animisme, iaitu roh sebagai satu kuasa yang besar dipercayai wujud dan keris Taming Sari punyai kuasa magis ini. Kuasa itu turut menyerap 
ke tubuh Hang Tuah. Selain Raja, Hang Tuah juga memiliki daulat dan daulat ini bukan kerana Hang Tuah itu keturunan keinderaan seperti Raja tetapi disebabkan keris Taming Sari itu ada nilai daulat. Nilai daulat yang dikaitkan dengan animisme ini dapat difahami dengan andaian yang mendasar, iaitu feudalisme. Nilai daulat yang boleh ditafsirkan pada keris Taming Sari bukanlah satu nilai yang biasa. Nilai daulat yang ditafsirkan daripada keris Taming Sari ada kaitan dengan unsur magis. Nilai magis pada keris Taming Sari berkaitan dengan roh atau semangat seperti yang dipercayai dalam animisme. Para Raja Melayu termasuklah Raja Melaka berasal daripada keturunan keinderaan atau kayangan. Maka dengan asal keturunan dari kayangan maka Raja Melaka mempunyai daulat yang ada unsur magis. Kedaulatan ini disokong dengan kehadiran keris Taming Sari yang juga mempunyai nilai magis. Rakyat menerima Raja sebagai raja yang berdaulat dan berlindung serta memberikan kesetiaan yang tidak berbelah bahagi kepada Raja. Dengan menggunakan kod budaya perkaitan nilai daulat itu dengan animisme dan feudalisme itu dapat difahami dengan lebih jelas.

Mengikut Cheah Boon Kheng (1991, p. 28), terdapat beberapa ciri feudalisme masyarakat Melayu tradisional berbanding feudalisme Barat. Feudalisme Melayu antaranya; saling bergantungan antara Raja dan rakyat walaupun lebih berat kepada Raja. Pembesar daerah pula adakalanya lebih kuat berbanding Raja apabila pembesar tersebut diberikan hak untuk memerintah daerahnya berbanding dengan feudalisme Barat yang bersifat sehala sahaja. Walau bagaimanapun, Cheah tidak membincangkan hubungan antara feudalisme dan daulat. Konsep daulat yang ada unsur magis ini membentuk hubungan Raja dan rakyat. Jika Raja mendapat daulat daripada asal usul keinderaannya, Hang Tuah mendapat daulat daripada keris Taming Sarinya. Seperti pendapat Cheah, wujud hubungan saling bergantung antara Raja dan Rakyat, begitu juga antara Hang Tuah dan Raja Melaka. Raja bergantung pada Hang Tuah dan begitulah sebaliknya. Kehilangan mahkota Sultan dan keris Taming Sari yang jatuh ke dalam sungai telah memberikan kesan kepada Sultan dan Hang Tuah. Kehilangan daulat membawa kepada kehilangan feudalisme. Dengan kata lain, feudalisme tidak berfungsi tanpa daulat.

\section{KESIMPULAN}

Kesimpulannya, dalam Hikayat Hang Tuah, keris Taming Sari dianggap sebagai satu organisasi yang mempunyai tiga lapisan budaya yang mempunyai maknanya yang tertentu. Tahap pencarian makna pada setiap peringkat itu berbeza. Lapisan pertama 
ialah lapisan artifak, iaitu pencarian maknanya mudah kerana makna itu jelas. Dalam konteks keris Taming Sari, lapisan pertamanya ialah bentuknya dan hal ini dapat diperhatikan. Keris Taming Sari mempunyai bentuk yang dibahagikan kepada tiga bahagian, iaitu hulu, sarung dan mata. Hulu itu pemegangnya, sarung itu berfungsi untuk menjadi pelindung dan mata itu ialah objek tajam yang mempunyai fungsi tertentu. Namun begitu, bahagian-bahagian pada bentuknya itu tidak dirincikan berbanding dengan bahagian keris yang dimiliki oleh Sultan Mansor Syah misalnya. Hal ini mungkin untuk membezakan keris milik rakyat berbanding keris milik raja atau sultan. Lapisan kedua ialah lapisan nilai. Nilai ini didapati daripada persetujuan ramai. Nilai keris Taming Sari pada peringkat ini berkaitan dengan fungsinya. Terdapat dua fungsi pada keris Taming Sari, iaitu fungsi senjata dan anugerah atau hadiah. Keris Taming Sari digunakan sebagai senjata dan fungsinya jelas dapat diperhatikan dalam pertarungan antara Hang Tuah dengan Taming Sari dan Hang Tuah dengan Hang Jebat. Apabila Hang Tuah dapat menewaskan Taming Sari, Seri Bentara Majapahit memberikan keris itu kepadanya sebagai anugerah atas jasanya membunuh pendekar Taming Sari yang mengamuk di peseban istana Majapahit. Pada peringkat lapisan ketiga, makna tersembunyi dan sukar diperoleh maka pendekatan semiotik digunakan. Kod tanda digunakan mencari makna di sebalik lapisan ketiga itu. Dengan menggunakan kod simbol, keris Taming Sari ditafsirkan sebagai simbol magis dan daulat. Kod simbol ini dimantapkan dengan kod budaya. Melalui kod budaya, keris Taming Sari memperlihatkan makna yang berkaitan dengan animisme dan feudalisme. Dengan kata lain, melalui kod tanda, keris Taming Sari memperlihatkan nilai magis dan daulat yang berpaksikan pemikiran animisme dan feudalisme. Dua pendekatan, iaitu budaya dan semiotik yang digunakan untuk mencari makna keris Taming Sari memperlihatkan pemaknaan yang jelas tentang keris Taming Sari seperti yang terdapat dalam Hikayat Hang Tuah.

\section{RUJUKAN}

Barthes, Roland. (1991). S/Z (terj. Richard Miller). Cetakan ke-18. New York: The Noonday Press.

Cheah Boon Kheng. (1991). Feudalisme Melayu: Ciri-Ciri dan Pensejarahannya. Siri Syarahan Perlantikan Profesor 1991. Universiti Sains Malaysia.

Hikayat Hang Tuah. (1997). (Dikaji dan Diperkenalkan oleh Kassim Ahmad dengan Pengenalan Tambahan oleh Noriah Mohamed). Kuala Lumpur: Yayasan Karyawan dan Dewan Bahasa dan Pustaka. 
Ki Hudoyo Doyodipuro, Occ. (2000). Keris. Daya Magik-Manfaat-Tuah-Misteri (Cetakan Kelima). Semarang: Dahara Prize.

Mas Djomul. (1985). Keris Benda Budaya. Jakarta: Aksara Baru.

Mas Ngabehi Wirasoekadga. (1988). Misteri Keris. Semarang: Dahara Prize

McGee, R. John and Warms, Richard L. (2008). Anthropological Theory. An Introduction History. New York: Mc Graw Hill.

Mohamad Nazri Ahmad. (2000). Batik dan Seni Ukur Keris. Kuala Lumpur: Pustaka Mawar.

Noriah Mohamed. (1997). Pengenalan Tambahan dalam Hikayat Hang Tuah (pp. xxviix1viii). Kuala Lumpur: Yayasan Karyawan dan Dewan Bahasa dan Pustaka. hlm.

Shahrum bin Yub. (1967). Keris dan Senjata2 Pendek. Kuala Lumpur: Dewan Bahasa dan Pustaka.

Schein, Edgar H. (1984). Coming to a New Awareness of Orgabizational Culture. Sloan Management Review, 25(2), (Winter), 3-16. Akses pada 14 Ogos 2018, daripada http:// www.sietmanagement.fr/wp-content/uploads/2016/04/culture_schein.pdf

Tengku Intan Marlina Tengku Mohd Ali dan Salinah Ja'afar. (2013). Simbol Kebesaran Daulat, Mahkota dan Keris dalam Hikayat Hang Tuah. Jurnal Melayu 11, Dis., 99109.

Tylor, Edward. B. (1974). Primitive Culture Researches into Development of Mythology, Philosophy, Religion, Art and Custom. New York Gorden Press.

Woolley, G.C. (1938). Origin of the Malay Keris. Journal of the Malayan Branch of the Royal Asiatic Society, XVI, Part 2.

Tarikh Peroleh (received): 14 Ogos 2019

Tarikh Terima (accepted): 07 Julai 2020 